Review Article

www.ijrap.net

\title{
THE PRELUDE ON CONVENTIONAL AND ADVANCE TREATMENT OF PEMPHIGUS VULAGARIS (PV):
} A REVIEW

\author{
Basappa Karisetty ${ }^{1 *}$, Venu Gopal Jonnalagadda ${ }^{2}$ \\ ${ }^{1}$ Department of Pharmacy Practice, National Institute of Pharmaceutical Education and Research (NIPER), Gauhati, \\ Assam, India \\ ${ }^{2}$ Department of Pharmacology and Toxicology, National Institute of Pharmaceutical Education and Research (NIPER), \\ Gauhati, Assam, India
}

Received on: 14/10/13 Revised on: 06/11/13 Accepted on: 25/11/13

\begin{abstract}
*Corresponding author
E-mail: basappa.karisetty@gmail.com

DOI: 10.7897/2277-4343.04627

Published by Moksha Publishing House. Website www.mokshaph.com

All rights reserved.
\end{abstract}

\section{ABSTRACT}

The Pemphigus vulgaris (PV) is a group of highly lethal autoimmune disease characterized by mucocutaneous erosions or blisters. Pemphigus vulgaris can be present in different forms like oral and topical. So, it is challenging to manage and treat. Mortality rate due to Pemphigus vulgaris can be decreased by using systemic corticosteroids, but the present treatment options are limited due to the toxicity profiles of drugs available for treating Pemphigus vulgaris. Recent studies that shed light on the molecular mechanisms involved in the disease had lead to introduction of advance therapies like immunoadsorption, extracorporeal photochemotherapy (ECP), tumor Necrosis Factor- $\alpha$ (TNF- $\alpha$ ) treatment and few other treatments have been subject to randomized control trials to firmly establishes therapeutic efficacy. The present review emphasized on management of the condition, most commonly conventional treatments and recent treatment advances.

Keywords: Conventional and Advance therapy, Extracorporeal photochemotherapy, Immunoadsorption, Pemphigus Vulgaris, Rituximab.

\section{INTRODUCTION}

Pemphigus Vulgaris (PV) is a rare, chronic lifethreatening autoimmune blister disease of the skin and mucous membrane. ${ }^{1}$ It is caused by IgG autoantibody that binds to a membrane antigen (Dsg1/Dsg3) and is responsible for the release of a protease that leads to destruction of epidermal keratinocyte desmosomal caderins Dsg3/Dsg, resulting in loss of adhesion between the cells of epidermis, a phenomena called acantholysis. ${ }^{2}$ The exact cause of this was unknown. Acantholysis along with direct immunofluorescence (DIF) evaluation revealing the presence of IgG deposits in intraepidermal keratinocytes, with a honeycomb pattern. It is usually fatal if untreated. ${ }^{3}$ Females aged 40-60 years are mostly affected. Pemphigus vulgaris is a one of the more severe presentations that very often leads to serious patient conditions that are difficult to handle on an outpatient basis, and repeatedly requires intensive care. ${ }^{4}$ Pemphigus vulgaris has worldwide distribution affecting 0.1-0.5 patients per 100000 populations per year. In the United Kingdom, a regional study estimated an incidence of 1.4 per 100000 person years. ${ }^{5}$ Wide variation in mortality is reported, with one year mortality varying between $6 \%$ in the United States and $41 \%$ in France. In the few hospital based studies of the epidemiology of PV, the reported incidence varied between 0.076 and 1.6 per 100000 person years. A Pub med search (with search terns pemphigus and India) retrieved 96 articles (retrieved August 6, 2010) with earliest one dating back into 1960 in which Desai and Rao had described 21 cases of pemphigus. ${ }^{6}$ The Pemphigus vulgaris is frequently disaster with a death rate ranging from $65 \%$ to $90 \%$. while the use of systemic corticosteroids and other advanced therapeutic methods have been reduced approximately $10 \%$ of the mortality rate. ${ }^{7,8}$ The current mortality was about $6.2 \%$ (range 0 to $10 \%$ ) and did not show further significance reduction. ${ }^{9,10}$ Initially the minimum dose used for systemic therapy to control the disease, modifying the treatment by taking account of the general health and age of the individual patient and extent of the disease. Some while have more aggressive disease and need significant immunosuppressant. The mainstay of treatment remains to be corticosteroids with or without another adjuvant therapy. The adjuvant therapies include steroids sparing agents (immunosuppressive agents and anti-inflammatory agents), immunomodulatory procedures, Extracorporeal photo chemotherapy (ECP), Immunoadsorption, Tumor Necrosis Factor- $\alpha$ (TNF- $\alpha$ ) antagonist and cholinergic agonist therapies.

\section{Conventional Treatment}

Treatment first aims to acquire disease remission, and this is regularly possible as a result of intensive therapy (often on an in-hospital basis). Such management is then followed by maintenance therapy to stabilize the disease with the administration of systemic medication in gradually decreasing doses.

\section{Corticosteroids}

The oral corticosteroids (CS) are used for the management of Pemphigus vulgaris. The initiation of corticosteroids was in 1950. For the administration of corticosteroids in Pemphigus vulgaris there is no standardized approach, the most common method is oral corticosteroids. The recent study the outcomes have continued to improve the mortality was zero and $29 \%$ of patients' shows complete remission rate treated with steroids alone. On average, cessation of blistering takes 2- 
3 weeks and full healing may take $6-8$ weeks. ${ }^{11}$ The initial dose of prednisolone is $120-180 \mathrm{mg}$ per a day. The patients with severe Pemphigus vulgaris initial therapy with low- dose prednisolone 45-60 mg day were compared with high-dose prednisolone affecting more than $50 \%$ of their body surface. In 5 years duration there was no significant difference in remission and relapse rate. $^{12}$ According to disease severity a tailored dosing schedule has been recommended. ${ }^{11}$ The initial prednisolone doses of 40-60 $\mathrm{mg}^{-1}$ day $^{-1}$ used for the patient with disease and in more severe cases, $60-100 \mathrm{mg} \mathrm{day}^{-1}$. If there is no response within 5-7 days, the dose should be increased in 50-100\% increments until there is disease control. If dose above $100 \mathrm{mg}$ per a day is required, pulsed intravenous corticosteroids could be considered. ${ }^{10}$

\section{Pulsed intravenous corticosteroids}

The term "pulse" refers to discontinuous intravenous infusion of supra therapeutic drug doses in a short period of time. It achieve more rapid and effective disease control is main theoretical aim of pulsing. ${ }^{13}$ Pulse therapy is recommended as an adjuvant to the initial management plan for patients with more severe Pemphigus vulgaris involvement. Pulsed intravenous corticosteroids used for the intermittent administration of high dosed intravenous corticosteroids, usually methylprednisolone $250-1000 \mathrm{mg}$ or equivalent dose of dexamethasone given on one to five consecutive days. ${ }^{14}$ Patients with oral Pemphigus vulgaris have given Prednisolone/Cyclophosphamide (100 mg) and Prednisolone/Cyclosporine (5 $\mathrm{mg} / \mathrm{kg})$, in those patients for the remission and relapse rates there was no significant change. However, cyclophosphamide and cyclosporine were given for a small period of only 2-3 months. The side-effects mainly associated with the use of pulsed intravenous corticosteroids are

gonadal damage, teratogenicity, hemorrhagic cystitis, leucopenia and reversible alopecia and meylosuppression. $^{15}$

\section{Adjuvant Therapy}

One of the treatment options for Pemphigus vulgaris includes adjuvant drug therapy, which are agents that support the effect of steroids administered mainly via the oral route. Some of these adjuvants act as "steroid sparing agents". The foremost representatives are azathioprine and cyclophosphamide. Some of the characteristics of these drug substances will be dealt briefly.

\section{Azathioprine (AZT)}

Azathioprine (AZT) is used as an adjuvant drug in PV and also allowed to bring reduction in the dose of the steroid use and its side-effects. ${ }^{16,17}$ The complete remission rates of $28-45 \%$ and mortality rates of $1.4-7 \%$, exceeds in patients treated with CS alone. ${ }^{10}$ In some cases AZT was effectively used as a monotherapy to induce and maintain clinical remission with a fall in antibody titre. ${ }^{18}$ AZT doses of 1-3 mg/ $\mathrm{kg}^{-1}$ used in previous studies based on the individual activity of TPMT (Thiopurine MethylTransferease) should be titrated ideally. Patients with very low TPMT levels (1:200-300 of the general population) AZT are best avoided ${ }^{19}$ and dose should be reduced doses to $0.5 \mathrm{mg} / \mathrm{kg}^{-1}$. According to clinical and side-effects, the dose should be titrated upwards up to 3.5$4 \mathrm{mg} / \mathrm{kg}^{-1}{ }^{20}$ The side effects of AZT include bone marrow depression, liver dysfunction and increased incidence of malignancy. AZT is metabolized by TPMT and the low enzyme activity leads to accumulation of cytotoxic thiopurine metabolites which increase the risk of toxicity. $^{21}$

\section{Pulse cyclophosphamide}

Pulse therapy was first described by Pasricha and Ramji (father of pulse therapy) in $1984 .^{11}$ It defined as discontinuous or intermittent Intravenous infusion of very high doses (mega doses) of drugs over a short time on arbitrary. $^{22}$ The main aim of pulsing of cyclophosphamide is to achieve more effective and rapid control of disease compared with continuous drug, thus reduction in longterm maintenance corticosteroid doses and its side effects. $^{23}$ Though some authors feel that cyclophosphamide is more effective (an alkylating agent that disrupts cell growth and mitotic activity by cross linking DNA) compared to azathioprine, it is more difficult to use and has more lethal effects. ${ }^{10,24}$ A number of factors have contributed to the success and widespread acceptance of dexamethasone pulse therapy. One most important factor was the choice of corticosteroid. Conventionally, methylprednisolone was the agent most commonly used in corticosteroid pulse therapy. The choice of dexamethasone made the treatment considerably more affordable and accessible to patients. ${ }^{25,26}$ The high doses of intravenous CS and cyclophosphamide are administered intermittent, usually three daily doses of dexamethasone $(100 \mathrm{mg})$ or methylprednisolone (500$1000 \mathrm{mg}$ ) and single dose of cyclophosphamide 0.5-1.0 $\mathrm{g} / \mathrm{m}^{2}$ body surface area (starting dose 500-1000 mg and maximum dose $750-2000 \mathrm{mg}$ ) given monthly. 300 patients with pemphigus ( 250 with $\mathrm{PV})$ treated with dexamethasone and cyclophosphamide pulse (DCP) therapy at 4 weekly intervals. Overall, 190 patients (63 $\%$ ) achieved complete remission, $48 \%$ for more than 5 years. The overall mortality rate was less than $5 \%$. The steroid side-effects were very less but $62 \%$ of menstruating female (18 of 29) amenorrhoea and azoospermia was developed and $55 \%$ of patient (17 of 33) had pituitary-adrenal suppression. ${ }^{28}$ A study was conducted in All India Institute of Medical Sciences (AIIMS) Twenty-nine of the 30 patients in whom DCP was instituted showed a good response and completed phase I in an average of 8 pulses. ${ }^{29}$

\section{Cyclosporine}

Cyclosporine was useful adjuvant with steroid-sparing effects in $\mathrm{PV}^{30}$ Cyclosporine is an immunosuppressive agent with anti-T-cell lymphocyte activity. It inhibits production of interleukin-2 (IL-2) and interferon-gamma (IFN-g) by lymphocytes. ${ }^{21}$ Some recent single randomized, prospective, controlled trial studies on cyclosporine produced conflicting (an incompatible) results in 33 patients comparing methylprednisolone with cyclosporine $5 \mathrm{mg} / \mathrm{kg}^{-1}$ Vs. oral methylprednisolone. 1 $\mathrm{mg} / \mathrm{kg}$ alone found no statistically significant difference in outcome measures and there was no significant difference in terms of response, time required to control 
the disease and proportion of flare between two groups of patients taking steroid versus steroid plus cyclosporine. More side effects were encountered with cyclosporine during a mean follow-up period of 5 years. ${ }^{31}$ There were no deaths but some patients were in complete remission but showed some side-effects like renal function impairment (dose dependent increase in urea and creatinine in the first week), hypertrichosis, gingival hypertrophy and tremor. On the basis of current evidence, cyclosporine cannot be preferred as an adjuvant drug in $\mathrm{PV}^{32,33}$

\section{Methotrexate (MTX)}

It is most widely accepted as an adjuvant. The methotrexate used as a monotherapy for PV. Methotrexate (MTX) is an antimetabolite that suppresses DNA and RNA synthesis during the S-phase of cell cycle. The drug competitively inhibits dihydrofolatereductase (DHFR), which decreases the formation of tetrahydrofolate (THF), a cofactor important in de-novo purine and thymidylate synthesis. Patients should be started on a low dose (often with an initial test dose) and cautiously increased every week to the target dose. The high doses of MTX (up to $125 \mathrm{mg}$ a week are advised) combination with prednisolone $0.5-1.0 \mathrm{mg} / \mathrm{kg} /$ day to bring the disease under control within 6 months. ${ }^{34}$ In practice it is difficult to use because of its side effects (mainly at hepatic level) thus, MTX as adjuvant is reserved for those cases of PV in which it is not possible to use with some other adjuvant substance such as azathioprine or cyclophosphamide. ${ }^{35}$ The adverse effects reported were nausea and mild elevation of transaminase enzyme levels, meylosuppression, and stomatitis.

\section{Mycophenolate mofetil (MMF)}

Generally Mycophenolic acid used for the management of psoriasis during the last three decades, at present it has been re-formulated as mycophenolate mofetil (MMF) and used as an immunosupressor in transplantation patients (Food and Drug Administration (FDA) 1995). ${ }^{36}$ In recent years study found MMF to be useful in the management of ampullar lichen planus, systemic lupus erythematosus (SLE) and PV. ${ }^{37}$ The current uses of mycophenolate in PV (It inhibit the de novo pathway of purine synthesis in Tlymphocytes and B-lymphocytes) administered as coadjuvant daily doses of 2-2.5 g are typically given in to two divided doses with prednisolone to reduce the activity of PV. MMF shows only minimal side effects like diarrhoea, dyspepsia, nausea, myelosuppressive and those due to immunosuppression. ${ }^{38,39}$ Although it was initially used in monotherapy with positive effects over more than 6 months, it is now better used as adjuvant in case of active PV. MMF is recommended for recalcitrant cases, or when azathioprine and cyclophophamide cannot be used. $^{40,41}$

\section{Anti-Inflammatory Drugs Dapsone (DDS)}

Dapsone (DDS) is the one of most useful sulphonic antibiotic drug in application to many diseases, including leprosy. Mainly DDS was recommended to be an effective adjuvant to corticosteroids in $\mathrm{PV}^{42}$ DDS exhibits antibiotic effect, interferes with neutrophil chemotacitic migration (blocking myeloperoxidase activity), reduce the release of prostaglandins (PGs) and leukotrienes (LTs), inhibit neutrophil adherence to basement membranes, inhibit the generation of toxic radicals and protect cells from neutrophil (inhibits neutrophil toxicity) 1 and eosinophil-mediated injuries. The some of an experimental studies suggested that DDS exhibits no effects upon serum antibody levels in PV. ${ }^{43}$ It showed no significant use in monotherapy, but can be used as adjuvant. A common side effect of DDS includes heamolysis, methaemoglobinaemia, neuropathy and allergic dermatitis. ${ }^{44}$

\section{Gold}

Gold was first described in the treatment of PV since 1973. In most of studies gold was used intramuscularly (i.m) in PV, a dose of $50 \mathrm{mg} /$ week was used initially. If test dose is tolerated, it was used successfully as monotherapy. Gold (50 mg) was given weekly after test dose, and dose was reduced monthly when prednisolone was taken off. The complete remission rates were 15-44 $\%$ but side-effects lead to drug withdrawal in 17-35\% patients and it was found ineffective in $28 \%$ of case. Its use seemed to be decreased recently due to concerns of its safety and efficacy. Major side-effects of gold are dermatitis, diarrhea, oral ulcer, proteinuria, blood disorders, alopecia, peripheral neuritis, pulmonary fibrosis and cholestatic jaundice. ${ }^{45}$

\section{Plasmapheresis}

As the disease activity of PV generally correlates with the level of circulating autoantibodies, their removal seems a reasonable therapeutic approach. Plasmapheresis is mainly hypothesized to eliminate pathogenic autoantibodies and used in refractory cases of pemphigus. The disease activity of PV is generally estimated by the level of circulating autoantibodies and their removal seems a reasonable approach to treat PV and this can be done using plasmapheresis. The level of circulating antibodies was shown to increase as early as three hours after plasmapheresis. Therefore immunosuppressives are administered immediately after plasmapheresis to help achieve complete reduction. Patients who were treated with plasmapheresis and they followed by pulse cyclophosphamide or pulse methyl prednisolone with azathioprine showed some remission. ${ }^{46}$ The circulating intercellular antibody titres decreased on average by three fold, 60 days after plasmapheresis. There was no data comparing the choice of immunosuppressive agents and the results suggested that the timing and the individual's responsiveness to the agent was the key to reduce antibody level. $^{47}$

\section{Intravenous Immunoglobulins (IVIGS)}

Intravenous immunoglobulin (IVIG) is being increasingly used in immune-mediated diseases (mainly functional blockade of Fc receptors, elimination of immune complexes, anti-idiotypic suppression of autoantibodies, and inhibition of complement mediated damage). ${ }^{48,49}$ Doses of 1.2-2 $\mathrm{kg}^{-1}$ divided over 3-5 days were infused every 2-4 weeks. It was helpful in inducing a rapid 
remission and clinical improvement in some cases, but may be temporary unless repeated courses of IVIG are studied. $^{50,51}$ IVIG was initially used as an adjuvant therapy. There are important considerations for the use of IVIG. The drug is costly and often requires hospitalization for intravenous administration. There is no randomized control trial and the optimal dosage and regimen is yet to be determined. Long-term follow up data is important in defining its benefits. IVIG is usually well tolerated but the side effects include vasomotor symptoms such as headache, myalgia, flushing, and nausea. Anaphylactic shock may occur in patient with IgA deficiency. ${ }^{51}$

\section{Advance Treatment \\ Immunoadsorption (IA)}

Immunoadsorption (IA) is a relatively new treatment, which, unlike plasmapheresis specifically removes particular plasma components such as pathogenic immunoglobulins. Immunoadsorption consists of collecting patient plasma, passing it through an adsorber column (i.e., Protein A) to remove circulating immune complexes, IgG and returning the filtered plasma to the patient. $^{52}$ The evidence for this therapy is derived solely from case series, Luftl et al reported a series of nine pemphigus patients treated with Immunoadsorption in addition to their regular immunosuppressive therapy. ${ }^{53}$ Evaluation by ELISA revealed a $30 \%$ reduction of pathogenic IgG antibodies after a single Immunoadsorption treatment, all patients were clinically improved. Some patients were allowed to remain on concomitant one cycle of immunosuppressive therapies like azathioprine or MMF, IA resulted in decline of desmoglein-specific IgG autoantibodies resynthesis and a dramatic clinical response. ${ }^{54}$ More recently, a small case series demonstrated to achieve long-term remission. IA in combination with rituximab could be used. ${ }^{55}$

\section{Rituximab (RTX)}

Rituximab (RTX) is a chimeric murine/human IgG1 antiCD20 monoclonal antibody that targets pre-B and mature B lymphocytes, causing transitory B-cell depletion in patients suffering with $\mathrm{PV}$, which is unresponsive to conventional therapies or for patients in whom other drugs are contraindicated. RTX prevents the maturation of antibody-producing plasma cells by reducing circulating B cells. Multiple case reports suggest that an effective treatment option for PV is RTX. ${ }^{56}$ A study involving small series of patients treated on a regimen of four weekly infusions of RTX $375 \mathrm{mg} / \mathrm{m}^{2}$ showed significant results. Most adverse effects were infusion related and temporary, although death occurred in one patient and systemic infection in another three were observed. The RTX used in combination with IVIG is highly effective in a series of eleven patients with extensive controlled PV. In some case studies the clinical remission lasted between 22-27 months with combination therapy. ${ }^{57}$

\section{Extra corporeal photo chemotherapy (ECP)}

Extracorporeal Photochemotherapy (ECP) is also known as photopheresis, used in the treatment of patient following acute allograft rejection in cardiac, lung, renal, or liver transplantation, acute and chronic graft-versus- host disease (GvHD), systemic lupus erythematosus (SLE), rheumatoid arthritis (RA) and PV. ${ }^{58}$ Limited data has been published regarding the use of ECP in a variety of autoimmune diseases. The processes mainly involved in this leukapheresis means patient's white blood cells (WBC) were collected and exposed to 8methoxypsoralen, after that cells are irradiated with ultraviolet-light (UV) and re-infused into the patient. Finally ECP inhibits the production of pathogenic autoantibodies of B-lymphocytes. ${ }^{59}$ However, all three patients experienced relapses for which therapy with ECP was resumed. ${ }^{60}$ In these studies patient treated with ECP showed a significant clinical improvement and showed no adverse effects.

Tumour necrosis factor- $\alpha$ (TNF- $\alpha)$ antagonists

Tumour necrosis factor- $\alpha$ (TNF- $\alpha)$ antagonists are helpful for the treatment of PV. Recent investigational studies have demonstrated that TNF- $\alpha$ plays an important role in the acantholysis process. ${ }^{61}$ Two case reports stated that infiximab was used successfully against refractory PV. The clinical improvement of disease increased by the use of etanercept was shown by two additional case studies. Clinical trials for both infiximab and etanercept are currently underway. ${ }^{62,63}$

\section{Cholinergic agonists}

Research suggests that acetylcholine and its receptors are involved in the process of acantholysis in PV. ${ }^{64} \mathrm{Up}$ to now only 2 clinical studies have been performed. In a case study of 6 patients with active PV, the cholinergic agonist pyridostigmine bromide showed clinical improvement in $50 \%$ of patients. ${ }^{65}$ Two patients were able to control their disease with pyridostigmine bromide alone and 1 patient was able to remain in remission devoid of any medication. In a recent double-blind placebo controlled trial $3 \mathrm{PV}$ patients with a total of 64 lesions were treated with $4 \%$ pilocarpine gel reported a higher epithelialization index compared to placebo. ${ }^{66}$

\section{Topical epidermal growth factor (EGF)}

The topical epidermal growth factor (EGF) has been evaluated in double-blinded RCT (Randomized Control Trials) of $20 \mathrm{PV}$ patients. Patients had similar, symmetrical lesions treated with either EGF $10 \mu \mathrm{g} / \mathrm{g}$ in silver sulfadiazine cream or silver sulfadiazine cream alone. Lesions treated with topical EGF healed in a median of 9 days compared to control lesions which healed in a median of 15 days, with the difference found to be significant. Further studies are required to confirm these promising results before making an assessment of topical EGF in PV. ${ }^{67}$

\section{Other Experimental Therapies}

The other experimental therapies developed to suppress the production of anti-desmoglein 3 antibodies through inactivation and/or removal of disease-associated CD4+ T lymphocytes by using intravenous desmoglein 3 peptides. $^{68}$ A novel therapy, KC706 (Kemia, Inc.) is an oral allosteric p38 mitogen-activated protein kinase (p38MAPK) inhibitor. In a murine model of pemphigus p38MAPK inhibitor prevented blister formation. ${ }^{69}$ 
Clinical trials are underway to determine the safety and efficacy of KC706 in the management of PV.

\section{CONCLUSION}

While many treatments have been developed for Pemphigus Vulgaris (PV), none of them have been shown to offer absolute success in controlling the disease. The treatment of choice is steroidal therapy via the oral or intravenous route, which offers an adequate response and can be favorably modified after prognosis. Pulse therapy appears to be novel path breaking therapy for treating PV along with other autoimmune and systemic diseases. In India, most of the hospitals prefer pulse therapy to treat patients suffering with PV. Conventional immunosuppressive and anti-inflammatory agents such as azathioprine, mycophenolate mofetil and cyclosporine are associated with severe adverse events. At present research directed towards better understanding of PV pathogenesis and introduction of a number of advance therapies such as Immunoadsorption, RTX. TNF- $\alpha$ antagonists is showing potential in PV treatment and management. Randomized controlled trials are the need of the hour to established safety and efficacy of these newer therapies in the management of PV.

\section{REFERENCES}

1. Vickova Laskoska MT, Laskoski DS, Kamberova S, Caca Bija Novaska N, Volckova N. Epidemiology of pemphigus in Macedonia: A 15- year retrospective study (1990-2004). Int J Decmol 2007; 46: 253-258.

2. http://www.pemphigus.org/

3. Scully C, Challacombe SJ. Pemphigus vulgaris: update on etiopathogenesis, oral manifestations, and management. Crit Rev Oral Biol Med 2002; 13(5): 397-408. http://dx.doi.org/10.1177/ 154411130201300504

4. Scott KJ, McKinnon BJ. Pemphigus vulgaris: an acquired blistering disease. South Med J 2003; 96(6): 618-20. http://dx.doi.org/10.1097 /01.SMJ.0000060884.26016.78

5. Gudi VS, White MI, Cruickshank N, Herriot R, Edwards SL, Nimmo F, et al. Annual incidence and mortality of bullous pemphigoid in the Grampian region of north-east Scotland. $\mathrm{Br} \mathrm{J}$ Dermatol 2005; 153: 424-7. http://dx.doi.org/10.1111/j.13652133.2005.06662.x PMid: 16086760

6. Kanwar AJ, Dhar S. Factors responsible for death in pemphigus patients. J Dermatol 1994; 21: 655-9. PMid:7962969

7. Yeh SW, Ahmed B and Sami N, et al, Blistering disorders: disorders: diagnosis and treatment. Dematol Ther 2003; 16(3): 214 23. http://dx.doi.org/10.1046/j.1529-8019.2003.01631.x

8. Fiveson DP, Breneman DL, Rosen GB, Hersh CS, Cardone S, Mutasim D. Nicotinamide and tetracycline therapy of bulbous pemphigoid. Arch Dermol 1994; 130(6): 753-8. http://dx. doi.org/10.1001/archderm. 1994.01690060083010

9. Guillaume JC, Valliant L, Bernard P, et al. Controlled trial of azathioprine and plasma exchange in addition to predsolone in the treatment of bulbous pemphigoid. Arch Dematol 1993; 129(9): 4953. http://dx.doi.org/10.1001/archderm.1993.01680220061016

10. Bystryn JC, Steinmann NM. The adjuvant therapy of pemphigus. Arch Dermatol 1996; 132: 203-12. http://dx.doi.org/10.1001/ archderm. 1996.03890260105016

11. Lever WF, White H. Treatment of Pemphigus with corticosteroids. Results obtained in 46 patients over a period of 11 years. Arch Dermatol 1963; 87: 12-258. http://dx.doi.org/10.1001 /archderm. 1963.01590130018006 PMid:13930068

12. Ratnam KV, Phay KL, Tan CK. Pemphigus therapy with oral prednisolone regimen. Int J Dermatol 1990; 29: 363-7. http://dx. doi.org/10.1111/j.1365-4362.1990.tb04765.x PMid:2361795

13. Werth VP. Treatment of pemphigus Vulgaris with brief, high dose intravenous glucocorticoids. Arch Dematol 1996; 132: 1435-9. http://dx.doi.org/10.1001/archderm.1996.03890360021005

14. Chyssomallis F, Dimitriades A, Chaidemenos GC et al. Steroid pulse therapy in pemphigus vulgaris long term follow-up. Int J
Dermatol 1995; 34: 438-42. http://dx.doi.org/10.1111/j.13654362.1995.tb04450.x

15. Pandya AG, Sontheimer RD. Treatment of pemphigus vulgaris with pulse intravenous cyclophophamide. Arch Dermatol 1992; 128(12): 1626-30. http://dx.doi.org/10.1001/archderm.1992.04530010064010 http://dx.doi.org/10.1001/archderm.128.12.1626

16. Wolff K, Schreiner E. Immuno suppressive Therapie bei pemphigus vulgaris. Arch klin Exp Dermatol 1969; 235: 63-77. PMid:4981903

17. Burton JL, Greaves MW, Marks J, Dawber RPR. Azathioprine in pemphigus vulgaris. Br Med J 1970; 3: 84-6. http://dx.doi.org/ 10.1136/bmj.3.5714.84 PMid:4316981 PMCid:PMC1701060

18. Van DiJk TJA, Van Velde JL. Treatment of pemphigus and pemphigoid with azathioprine. Dermatologica 1973; 147: 179-85. http://dx.doi.org/10.1159/000251868

19. Holme SA, Duley J, Anstey AV. Thiopurine methyltransferase screening prior to azathioprine treatment in the United Kingdom. $\mathrm{Br}$ J Dermatol 2001; 145 (suppl.59): 12(Abstr.)

20. Nousari HC, Anhalt GJ. The role of mycopheolate mofetil in the management of pemphigus. J Am Acad Dermatol 1999; 135: 853-4.

21. Flores F, Kerdel FA. Other novel immunosuppressant. Dermatology Clinics 2000; 18: 475-83. http://dx.doi.org/10.1016/S0733-8635 (05)70195-9

22. Mentink LF, Markenzie MW, Toth GG, Lasner M, Lambeet FPG, Neeger $\mathrm{Nj}$, Cainchin $\mathrm{G}$, et al. Randomized controlled trails of adjuvant oral dexamethasone pulse therapy in pemphigus vulgaris. Arch Dermatol 2006; 142: 570-76. http://dx.doi.org/10.1001/ archderm.142.5.570 PMid:16702494

23. Harman KE, Albert S, Black MM. Guidelines for the management of pemphigus vulgaris BR. J Dermatol 2003; 149: 926-37. http://dx.doi.org/10.1111/j.1365-2133.2003.05665.x

24. Caffins ML, Collison D, Fiveson DP. Treatment of pemphigus and linear IgA dermatosis with nicotinamide and tetracycline. J Am Acad Dermatol 1993; 28: 998-1001. http://dx.doi.org/ 10.1016/S0190-9622(08)80651-2

25. Singh IP, Mehta SD. Pulse therapy in pemphigus vulgaris. Indian J Dermatol 1996; 41: 31-2.

26. Kaur S, Kanwar AJ. Dexamethasone cyclophosphamide pulse therapy in pemphigus. Int J Dermatol 1990; 29: 371-4. http://dx. doi.org/10.1111/j.1365-4362.1990.tb04767.x

27. Pasricha JS, Ramji G. pulse therapy with dexamethasone cyclophosphamide in pemphigus. Indian J Dermatol Verereol Leprol 1984; 50: 199-203.

28. Kumrah L, Ramam M, Shah $\mathrm{P}$ et al. Pituitary- adrenal function following dexamethasone -cyclophosphamide pulse therapy for pemphigus. $\mathrm{Br} \mathrm{J}$ Dermatol 2001; 145: 944-8. http://dx.doi.org /10.1046/j.1365-2133.2001.04524.x PMid:11899148

29. Rao P Narasimha, TSS Lakshmi. Pulse therapy and its modifications in pemphigus: A six year study. Indian Journal of Dermatology, Venereology and Leprology 2003; 69: 329-333. PMid: 17642930

30. Lapidoth M, David M, Ben Amitai D et al. The efficacy of combined treatment with prednisolone and cyclosporine in patients with pemphigus: preliminary study. J Am Acad Dermatol 1994; 30: 752-7. http://dx.doi.org/10.1016/S0190-9622(08)81506-X

31. Ioannides D, Chyssomallis F, Bystryn JC. In effectiveness of cyclosporine as an adjuvant to corticosteroids in the treatment of pemphigus. Arch Dermatol 2000; 136: 868. http://dx.doi.org /10.1001/archderm.136.7.868 PMid: 10890988

32. Lever WF, Goldberg HS. Treatment of pemphigus vulgaris with methotrexate. Arch Dermatol 1969; 100: 70-8. http://dx.doi.org /10.1001/archderm. 1969.01610250076018

33. Lever WF. Methotrexate and prednisolone in pemphigus vulgaris Therapeutic results obtained in 36 patients between 1961 and 1970 Arch Dermatol 1972; 106: 491-7. http://dx.doi.org/10.1001 /archderm. 1972.01620130023006

34. Smith TJ, Bystryn JC. Methotrexate as an adjuvant treatment for pemphigus vulgaris. Arch Dermatol 1999; 135(10): 1275-6. http://dx.doi.org/10.1001/archderm.135.10.1275

35. Harman KE, Albert S, Black MM. Guidelines for the management of pemphigus vulgaris. Br J Dermatol 2003; 149: 926-937. http:// dx.doi.org/10.1111/j.1365-2133.2003.05665.x PMid:14632796

36. Grundmann Kollmann M, Korting HC, Behrens S, Kaskel P, Leiter U, Krahn G, Kerscher M, Peter RU. Mycophenolate mofetil: a new therapeutic option in the treatment of blistering autoimmune diseases. J Am Dermatol 1999; 40: 957-960. http://dx.doi .org/10.1016/S0190-9622(99)70084-8 
37. Liu V, Mackool BT. Mycophenolate in dermatology. J Dermatolog treat 2003; 14(4): 203-11. http://dx.doi.org/10.1080/ 09546630310016826 PMid: 14660264

38. Mimouni D, Anhalt GJ, Cummins DL, Kouba DJ, Throne JE, Nousari HC. Treatment of pemphigus vulgaris and pemphigus foliaceus with mycophenolate mofetil. Arch Dermatol 2003; 139(6): 739-42. http://dx.doi.org/10.1001/archderm.139.6.739 PMid:128 10504

39. Nousari HC, Anhalt GJ. The role of mycophenolate mofetil in the management of pemphigus. J Am Acad Dermatol 1999; 135: 853-4.

40. Bredlich RO, Grundmann Kollmann M, Behrens S, Kerscher M, Peter RU. Mycophenolate mofetil monotherapy for pemphigus vulgaris. $\mathrm{Br} \mathrm{J}$ Dermatol 1999; 141(5): 934. http://dx.doi.org/ 10.1046/j.1365-2133.1999.03177.x PMid: 10583186

41. Bystryn JC. Is Mycophenolic acid effective for the management of pemphigus? Arch Dermatol 1999; 135(7): 854-5. http://dx.doi.org/10.1001/archderm.135.7.854 PMid:10411169

42. Huilgol SC, Black MM. Management of the immunobullous disorders. II.Pemphigus. Clin Exp Dermatol 1995; 20: 283-93. http://dx.doi.org/10.1111/j.1365-2230.1995.tb01301.x PMid: 8548984

43. Hashimoto K, Singer K, Lazarus GS. The effect of corticosteroids, dapsone and gold upon plasminogen activator synthesis and secretion by human epidermal cells cultured with pemphigus antibody. $\mathrm{Br} \mathrm{J}$ dermatol 1984; 110(3): 293-7. http://dx.doi. org/10.1111/j.1365-2133.1984.tb04634.x PMid:6421306

44. Bjarnason B, Skoglund C, Flosadottir E. Childhood pemphigus vulgaris treated with dapsone: a case report. Pediatr Dermatol 1998; 15(5): 381-3. http://dx.doi.org/10.1111/j.1525-1470.1998.tb01370.x PMid:9796590

45. Penneys NS, Eaglastein WH, Indgin S, Frost P .Gold sodium thiomalate treatment of pemphigus .Arch Dermatol 1973; 108: 5660. http://dx.doi.org/10.1001/archderm.108.1.56 PMid:4197772

46. Turner MS, Sutton D, Sauder DN. The use of plasmapheresis and immunosuppresision in the treatment of pemphigus vulgaris. J Am Dermatol 2000; 43: 1058-64. http://dx.doi.org/10.1067/mjd.2000 109297 PMid: 11100023

47. Roujeau JC, Andre C, Joneau Fabre M, et al. Plasma exchanger in pemphigus. Uncontrolled study of ten patients. Arch Dermatol 1983; 119: 215-21. http://dx.doi.org/10.1001/archderm.119.3.215 PMid: 6824359

48. Tappeiner G, Steiner A. High-dosage intravenous gamma globulin: therapeutic failure in pemphigus and pemphigoid. J Am Acad Dermatol 1989; 20: 684-5. http://dx.doi.org/10.1016/S01909622(89)80148-3

49. Rutter A, Luger TA. High dose intravenous immunoglobulins: an approach to treat severs immune-mediated and autoimmune disease of the skin. J Am Dermatol 2000; 43: 1049-57.

50. Messer G, Sizmann N, Feucht H, Maurer M. High-dose intravenous immunoglobulins for immediate control of severe pemphigus vulgaris. Br J Dermatol 1995; 133: 1010-18. http://dx.doi.org/ 10.1111/j.1365-2133.1995.tb06952.x

51. Harman KE, Black MM. High-dose intravenous immune globulin for the treatment of autoimmune blistering disease: an evaluation of its use in 14 cases. Br J Dermatol 1999; 140: 865-74. http:// dx.doi.org/10.1046/j.1365-2133.1999.02817.x

52. Akhtar SJ, Hassan MU. Treatment of pemphigus: a local experience. J Pak Med. Assoc 1998; 48(10): 300-304. PMid: 10087750

53. Eming R, Rech J, Barth S et al. Prolonged clinical remission of patient with severe pemphigus upon rapid removal of desmogleinreactive autoantibodies by Immunoadsorption. Dermatology 2006; 212(2): 177-187. http://dx.doi.org/10.1159/000090659 PMid:164 84825

54. Ogata K, Yasuda K, Matsushita M, et al. Successful treatment of adolescent pemphigus vulgaris by Immunoadsorption method. J Dermatol 1999; 26(4): 236-9. PMid:10343469
55. Shimanovich I, Nitschle M, Rose C, et al. Treatment of severe pemphigus with protein A Immunoadsorption, rituximab and intravenous immunoglobulins. Br J Dermatol 2008; 158(2): 382-8. http://dx.doi.org/10.1111/j.1365-2133.2007.08358.x PMid:18070 210

56. Schmidt E, Hunzelmann N, Zillikens D, et al. Rituximab in refacotory autoimmune bullous disease. Clin Exp Dermatol 2006; 31(4): 503-8. http://dx.doi.org/10.1111/j.1365-2230.2006.02151.x PMid: 16716150

57. Ahmed AR, Spigelman Z, Cavacini LA, et al. Treatment of pemphigus vulgaris with rituximab and intravenous immunoglobulin. $\mathrm{N}$ Eng $1 \mathrm{~J}$ Med 2006; 355(17): 1772-9. http://dx.doi.org/10.1056/NEJMoa062930 PMid:17065638

58. Rook AH, Jegasothy BV, Heald P, Nahass GT, et al. Extracorporeal photochemotherapy for drug-resistant pemphigus vulgaris. Ann Intern Med 1999; 112: 303-305. http://dx.doi.org/10.7326/00034819-112-4-303

59. Yeh SW, Sami N, Ahmed AR. Treatment of pemphigus vulgaris: current and emerging option, Am Dermatol 2005; 6(5): 327-42. http://dx.doi.org/10.2165/00128071-200506050-00006

60. Oliven A, Schechter Y. Extracorporeal photopheresis: a review. Blood Rev 2001; 15: 103-8. http://dx.doi.org/10.1054 blre.2001.0155 PMid:11409910

61. Feliciani $\mathrm{C}$, Toto $\mathrm{P}$, Americo $\mathrm{P}$, et al. In vitro and in vivo expression of interleukin-1 alpha and tumor necrosis factor-alpha mRNA in pemphigus vulgaris: interleukin-1 alpha and tumor necrosis factoralpha are involved in acantholysis. J Invest Dermatol 2000; 114(1): 71-77. http://dx.doi.org/10.1046/j.1523-1747.2000.00835.x PMid:1 0620118

62. Berookhim B, Fischer HD, Weinberg JM. Treatment of recalcitrant pemphigus vulgaris with tumor necrosis factor alpha antagonist etanercept. Cutis 2004; 74(4): 245-7. PMid: 15551718

63. Lin MH, Hsu CK, Lee JY. Successful treatment of the recalcitrant pemphigus vulgaris and pemphigus vegetans with etanercept and carbon dioxide laser. Arch Dermatol 2005; 141(6): 680-2. http://dx.doi.org/10.1001/archderm.141.6.680 PMid:15967912

64. Dick SE, Werth VP. Pemphigus: a treatment update. Autoimmunity 2006; 39(7): 591-9. http://dx.doi.org/10.1080/08916930600972008 PMid:17101503

65. Grando SA, Dahl MV. Activation of kerainocyte muscarinic acetylcholine receptors reverses pemphigus acantholysis. J Eur Acad Dernatol Venereol 1993; 2(2): 72-86. http://dx.doi.org/10.111 1/j.1468-3083.1993.tb00016.x

66. Iraji F, Yoosefi A. Healing effect of pilocarpine gel $4 \%$ on skin lesions of pemphigus vulgaris. Int J Dermatol 2006; 45(6): 743-6. http://dx.doi.org/10.1111/j.1365-4632.2006.02766.x PMid:16 796640

67. Kaufman DB, Shapiro R, Lucey WS, T Bustami R, Dyke DB. Immunosuppresision: practice and trends. Am J Transplant 2004; 4(9): 38-53. http://dx.doi.org/10.1111/j.1600-6135.2004.00397.x PMid: 15113354

68. Anhalt G, Werth V, Strober B, et al. An open -label phase I clinical study to assess the safety of PI 0824 in patients with pemphigus vulgaris. J Invest Dermatol 2005; 125(5): 1088

69. Berkowitz P, Hu P, Warren S, et al. p38MAPK inhibition prevents disease in pemphigus vulgaris mice. Proc Natl Acad Sci USA 2006; 103(34): 12855-60. http://dx.doi.org/10.1073/pnas.0602973103 PMid:16908851 PMCid:PMC1568937

Cite this article as:

Basappa Karisetty, Venu Gopal Jonnalagadda. The prelude on conventional and advance treatment of Pemphigus vulagaris (PV): A Review. Int. J. Res. Ayurveda Pharm. 2013;4(6):906-911 http://dx.doi. org/10.7897/2277-4343.04627 